\title{
A industrialização de São Gonçalo e a Companhia Nacional de Cimento Portland (1931/1942)
}

The industrialization of São Gonçalo and the National Cement Company Portland (1931/1942)

La industrialización de São Gonçalo y la Compañía Nacional de Cemento

Portland (1931/1942)

L'industrialisation de São Gonçalo et de la Compagnie Nationale de Ciment

Portland (1931/1942)

\section{Rafael Vaz da Motta Brandão}

\section{(2) OpenEdition}

\section{Journals}

Edição electrónica

URL: http://journals.openedition.org/espacoeconomia/3427

DOI: $10.4000 /$ espacoeconomia.3427

ISSN: 2317-7837

Editora

Núcleo de Pesquisa Espaço \& Economia

Refêrencia eletrónica

Rafael Vaz da Motta Brandão, «A industrialização de São Gonçalo e a Companhia Nacional de Cimento Portland (1931/1942) », Espaço e Economia [Online], 12 | 2018, posto online no dia 14 julho 2018, consultado o 30 abril 2019. URL : http://journals.openedition.org/espacoeconomia/3427 ; DOI : 10.4000/espacoeconomia.3427

Este documento foi criado de forma automática no dia 30 Abril 2019.

(C) NUPEE 


\section{A industrialização de São Gonçalo e a Companhia Nacional de Cimento Portland (1931/1942)}

The industrialization of São Gonçalo and the National Cement Company Portland (1931/1942)

La industrialización de São Gonçalo y la Compañía Nacional de Cemento

Portland (1931/1942)

L'industrialisation de São Gonçalo et de la Compagnie Nationale de Ciment

Portland (1931/1942)

Rafael Vaz da Motta Brandão

\section{A indústria do cimento no Brasil}

1 Segundo publicação do Sindicato Nacional da Indústria do Cimento - SNIC, a palavra "cimento" tem a sua origem no latim caementu, que na antiguidade Roma significava "uma espécie de pedra natural de rochedos não esquadrejada" (SINDICATO NACIONAL DA INDÚSTRIA DO CIMENTO, 2016, p. 1). O produto é a base do concreto, sendo, na atualidade, o segundo material mais utilizado pelo homem, atrás apenas da água.

2 É a partir do final do século XVIII, como o advento da Revolução Industrial, que a produção do cimento ganha novo impulso "quando cientistas europeus se empenharam em descobrir a fórmula perfeita para se obter o ainda pouco desenvolvido cimento hidráulico". A necessidade de desenvolver materiais que servissem de matéria-prima para argamassas de revestimento externo levaria ao aperfeiçoamento de algumas fórmulas e denominações diferentes, como cimento "romano" e cimento "britânico".

Na década de 1820, o químico e empresário inglês do setor de construção, Joseph Aspdin patenteou "o processo de fabricação de um ligante que resultava da mistura, calcinada em proporções certas e definidas, de calcário e argila" (SINDICATO NACIONAL DA INDÚSTRIA 
DO CIMENTO, 2016, p. 1), dando o nome de cimento "portland". A partir de então, seu uso e comercialização passaram a crescer, tendo em vista que "a ampliação dos processos de urbanização e de industrialização em escala mundial levou ao uso intenso do cimento nas atividades de construção civil" (PROCHNIK, 1985, p. 424).

Em 1855, o inventor francês Joseph-Louis Lambot apresentou, na Exposição Universal de Paris, o "cimento armado". Manteria essa denominação até as primeiras décadas do século XX, quando passou a ser chamado de "concreto armado".

No Brasil, ainda durante o período do Império, temos as primeiras tentativas de implantação de uma indústria nacional de cimento. Em 1888, em São Paulo, o engenheiro Loius Nóbrega e o comendador Antonio Prost, deram início à construção da fábrica de Rodovalho. A fábrica, que extraía calcário das grandes pedreiras localizadas na região de Sorocaba, entrou em operação em 1897 e, depois de ter mudado de proprietário por diversas vezes, teve o seu funcionamento paralisado em 1904. Em 1907, novamente passou a operar - lançando no mercado os produtos com as marcas "Lage", "Torquês" e "Meia Lua" - para, definitivamente, encerrar as suas atividades em 1918.

6 Também em 1888, na Paraíba, foi projetada pelo engenheiro Louis Felipe Alves da Nóbrega uma fábrica na Ilha de Tiriri. A unidade instalada em 1892 funcionou por apenas três meses, encerrando, então, as suas atividades. 0 seu fracasso estava relacionado, sobretudo, à baixa produção e à distância dos centros consumidores, o que impedia a competição com os cimentos importados na época. Conforme Paulo Cesar Machado Feitosa, "se as duas experiências não tiveram condições de se estabelecerem, grande parcela de responsabilidade por ser imputada à precariedade do equipamento e do processo de produção adotado" (FEITOSA, 1982, p. 37).

7 A terceira tentativa de implantação de uma indústria de cimento no país ocorreu em 1912, no Espírito Santo, quando "foi iniciado um empreendimento de responsabilidade do governo estadual, onde iria funcionar o $1^{\circ}$ forno rotativo do país, na cidade de Cachoeiro do Itapemirim" (FEITOSA, 1982, p. 37-38). Contudo, devido a sua precariedade e baixa produção (produzia apenas 8.000 toneladas por ano), a fábrica Cimento Monte Líbano, nunca chegou a funcionar regularmente tendo paralisado suas atividades em 1924, quando foi arrendada e remodelada. Desde então, funcionava com paralisações regulares até encerrar definitivamente suas atividades em 1958.

8 Segundo Leandro Bruno Santos, quatro fatores apontam para a dificuldade de consolidação da indústria do cimento no Brasil. Em primeiro lugar, tal atividade econômica apresenta uma grande dependência de matérias primas, sobretudo, de calcário e argila, nas proximidades da unidade fabril. Em segundo e diretamente ligado ao primeiro fator, no início do século XX, as principais reservas conhecidas de calcário e argila encontravam-se distantes dos principais mercados consumidores, como Rio de Janeiro e São Paulo. Terceiro, a infraestrutura de transportes no Brasil, naquele período, ainda era extremamente deficiente, o que tornava custoso o deslocamento do produto. Por fim, em quarto lugar, o cimento era isento de importação, o que desestimulava a abertura de novas fábricas de cimento nacionais, além dos pioneirismos citados (SANTOS, 2011, p. 78).

9 A implantação da indústria de cimento no Brasil ocorreu em um contexto de grandes obras de remodelação de cidades como Rio de Janeiro e São Paulo, acarretando um crescente consumo do cimento no país. Leandro Bruno Santos destaca que a urbanização e o crescimento do mercado interno, a entrada de capital e tecnologia estrangeiras, 
investimentos em outros setores econômicos presentes no país e o apoio do Estado são os principais fatores para a instalação de fábricas de cimento no Brasil (SANTOS, 2011, p. 80).

O país importava - na virada do século XIX para o XX - cerca de 40.000 toneladas de cimento, procedente, em sua grande maioria, de países europeus. Esse contexto estimulou fortemente o interesse de empresários brasileiros na instalação, no Brasil, de uma indústria do setor de cimento.

11 Victor Prochnik estabelece três fases distintas acerca da indústria do cimento no Brasil (PROCHNIK, 1985, p. 426): 1) a primeira, entre 1926 e 1942, corresponde à emergência da indústria de cimento no país, com a fundação da Companhia Brasileira de Cimento Portland e quando a parcela de importação no consumo aparente é reduzida de $100 \%$ para menos de 10\%; 2) a segunda, entre 1942 e 1967, quando ocorre a consolidação desse setor industrial, na qual adquire uma configuração de certa estabilidade; 3) e a terceira, entre 1968 e 1983, abrangendo o ciclo do "milagre" econômico de finais da década de 1960 e início da década seguinte, quando a demanda do setor da construção civil cresceu exponencialmente durante a ditadura civil-militar (CAMPOS, 2014).

12 A emergência da indústria de cimento, no Brasil, segundo o autor, está intimamente ligada ao crescimento da construção civil na década de 1920. De acordo com Prochnik, "o consumo aparente de cimento cresce a uma taxa de $15,5 \%$ ao ano entre 1920 e $1929 \mathrm{~m}$, e uma taxa ainda superior se for considerado apenas o período 1925/1929" (PROCHNIK, 1985, p. 427).

O ano de 1926 é, portanto, o marco histórico da indústria de cimento no Brasil. Naquele ano, foi inaugurada a Companhia Brasileira de Cimento Portland, empresa majoritariamente de capital estrangeiro. Até aquele momento, o Brasil importava em torno de $97 \%$ do cimento que consumia, sobretudo de países como Estados Unidos, Inglaterra, França, Alemanha, Dinamarca, Bélgica e Argentina (SINDICATO NACIONAL DA INDÚSTRIA DO CIMENTO, 2016, p. 2). A CBCP, que adotava fornos longos de via seca e equipamentos Allis Chalmers, de origem norte-americana, teve, posteriormente, o seu controle transferido para o capital privado nacional: em 1973, depois de sofrer intervenção do governo federal, passou a ser controlada pelo grupo Abdala (FEITOSA, 1982, p. 43). A Companhia Brasileira de Cimento Portland - CBCP, projetada para uma capacidade de produção de 60.000 toneladas, com extensão prevista para 125.000 , no prazo de seis meses e de 200.000 em 1930, ficava localizada na região de Perus, distante 23 quilômetros do centro de São Paulo. A fábrica foi instalada na região devido à "descoberta de ótimas reservas de calcário e a proximidade do maior centro consumidor de cimento, São Paulo, que passava por uma profunda transformação urbana" (SANTOS, 2011, p. 79). A instalação desta fábrica "representou o início do processo de crescimento da produção brasileira de cimento, que saltou imediatamente de 13.000 toneladas em 1926 para 54.000 em 1927, 88.000 em 1928 e 96.000 em 1929" (SINDICATO NACIONAL DA INDÚSTRIA DO CIMENTO, 2016, p. 3).

14 Segundo Prochnik, entre 1926, "(quando a produção nacional atingiu 3,4\% do consumo aparente); e 1943, (quando 97,9\% do cimento consumido forma produzidos internamente), cinco outras fábricas entraram em operação, sendo uma de propriedade norte-americana e quatro nacionais, que se instalaram após as duas estrangeiras" (PROCHNIK, 1985, p. 428).

Em 1933, sete anos depois da inauguração da fábrica de Perus, entrou em funcionamento uma fábrica em Guaxindiba, na cidade fluminense de São Gonçalo. A Companhia Nacional 
de Cimento Portland - CNCP, produtora da marca "Mauá" e nosso objeto de estudo neste artigo, era controlada pelo grupo norte-americano Lone Star Industries, um dos maiores produtores mundiais de cimento e com importantes ativos na América Latina (SANTOS, 2011, p. 79). A CNCP extraía o calcário da do município vizinho de Itaboraí, contando com ferrovia e porto próprios.

16 A partir da segunda metade da década de 1930 até o ano de 1942, quatro outras fábricas de cimento - todas controladas pelo capital nacional - entraram em funcionamento no país: 1) a Dolaport (1935) e incorporada ao grupo Matarazzo em 1944; 2) a fábrica da S. A. Indústrias Votorantim (1936), com capacidade de produção de 175.000 toneladas; 3) a Companhia de Cimento Portland Itaú (1939), do município mineiro de Itaú e que em 1997 passou a ser controlada pelo grupo Votorantim em 1977; e a 4) Pôty, em 1942 (FEITOSA, 1982, p. 46).

\section{A região de São Gonçalo e o processo de industrialização na década de 1930}

O município de São Gonçalo está situação a lesta da Baía da Guanabara, fazendo divisa com as cidades de Niterói, Itaboraí e Maricá. Segundo dados do IBGE de 2016, sua população era de 1.044.056 habitantes, o que fazia de São Gonçalo a segunda cidade mais populosa do Estado do Rio de Janeiro, perdendo apenas para a capital.

Com uma economia eminentemente rural até o inicio do século XX, São Gonçalo contava, por volta de 1860, com aproximadamente 30 engenhos para a produção de açúcar (dentre eles Engenho Novo, Engenho do Roçado, Engenho Pequeno, Engenho do Colubandê, nomes atuais de bairros do município). Grande parte da produção era escoada por diversos pequenos portos da região (Porto do Rosa, Porto Novo, Porto Velho, porto de Gaxindiba, também nomes de bairros gonçaleses). Segundo Hildete Melo e Victor Araújo, "com localização geográfica privilegiada, na entrada da Baía de Guanabara, São Gonçalo ainda exercia um papel importante servindo como elo de ligação com o interior da Província do Rio de Janeiro" (ARAÚJO e MELO, 2014, p. 69).

Em 1890, São Gonçalo deixou de ser distrito de Niterói, sendo elevado, pela primeira vez, à categoria de município. Contudo, em 1892, voltou a ser incorporada à cidade de Niterói. Permaneceu assim até 1923, quando retornou à condição de vila. Em 1929, pela Lei $n^{\circ}$ 2335, finalmente, São Gonçalo passou a ter a sua autonomia reconhecida.

É justamente nesse período, a partir da década de 1930, que São Gonçalo passaria por um intenso processo de urbanização e de industrialização. De acordo com dados disponibilizados pelo IBGE, ao final dos anos de 1930, São Gonçalo contava com 95 estabelecimentos industriais, responsáveis por uma variada produção de artigos industrializados: cimento, fósforos, rebites, pregos, panela de ferro, aço laminado, soda cáustica, cloro, cloreto de cálcio, vidros, louças, conserva de peixes, tintas, vernizes, formicida, telhas, tijolos, manilhas, artefatos de madeira e cimento armado, doces, bebidas, ouros curtidos, chocolate, caixas de papelão, vassouros, sal refinado, massas alimentícias, perfumes, produtos farmacêuticos, dinamite, fogos de artifício, sabão, móveis, calçados, louça de barros, essências, brinquedos, etc.

21 Nesse período, importantes indústrias se instalaram na cidade, entre as quais, podemos destacar a Companhia Nacional de Cimento Portland (CNCP), que contava com estrada de ferro e uma usina elétrica própria; Companhia Brasileira de Usinas Metalúrgicas 
(Siderúrgica Hime); Companhia Brasileira de Fósforos (Fiat Lux); Companhia Eletroquímica Fluminense; Indústrias Reunidas Mauá; Conserva de Sardinhas Coqueiro; Conserva Rubi; Companhia Nacional de Explosivos; Companhia Composições Internacional do Brasil; Fábrica de Formicida; Companhia Vidreira do Brasil; Fábrica de Soda Cáustica; Fábrica de Bebidas Rum Merino; Companhia Brasileira de Produtos de Pesca; as cerâmicas Vista Alegre, Fatori, Porto do Rosa, Pugliese e Esperança; as fábricas de doces Sublime e Regina; e as fábricas de brinquedos Fama e Fênix, entre outras.

22 José Honorato Lessa destaca que a industrialização em São Gonçalo, a partir da última década do século XIX, tornou-se possível a partir de fatores como a conquista da autonomia política e administrativa e a isenção fiscal para a instalação de fábricas na cidade. Segundo o autor, "nas formas de incentivos através de isenções de determinadas categorias de impostos municipais que somadas às outras condições já apontadas mostraram-se fundamentais na implantação das indústrias" (LESSA, 2010, p. 51).

A dimensão, diversificação e produtividade de seu parque industrial, produziram certo sentimento ufanista que levou a cidade a ser chamada de "Manchester Fluminense", uma referência à cidade inglesa, berço da Revolução Industrial no século XVIII. Porém, para Victor Araujo e Hildete de Melo, a participação da cidade no produto industrial estadual, teve uma participação limitada, pois entre 1940-1950 foi substancialmente reduzida (ARAÚJO e MELO, 2014, p. 74).

Abaixo, apresentamos dados referentes à produção de fósforo (caixas), cimento, ferro e aço (toneladas) para o período entre 1935 e 1939. Nesse período, a produção de caixas de fósforos aumentou de 120.265 para 151.776 caixas. A produção de cimento passou de 168.216 para 269.816 toneladas. Ferro e aço tiveram, respectivamente, um aumento de 14.588 e 17.709 para 19.486 e 21.923 toneladas.

Tabela 1: Produção de fósforo (1935/1939)

\begin{tabular}{ccc}
\hline Anos & Produção (caixas) & Índice $(1935=100)$ \\
\hline 1935 & 120.265 & 100 \\
\hline 1936 & 139.391 & 115 \\
\hline 1937 & 148.632 & 123 \\
\hline 1938 & 141.081 & 117 \\
\hline 1939 & 151.776 & 126 \\
\hline
\end{tabular}

Fonte: (PALMIER, 1940, p. 178). 
Tabela 2: Produção de cimento (1935/1939)

\begin{tabular}{ccc}
\hline Anos & Produção (toneladas) & Índice $(1935=100)$ \\
\hline 1935 & 168.216 & 100 \\
\hline 1936 & 225.454 & 134 \\
\hline 1937 & 239.785 & 142 \\
\hline 1938 & 250.937 & 149 \\
\hline 1939 & 269.816 & 160 \\
\hline
\end{tabular}

Fonte: (PALMIER, 1940, p. 177)

Tabela 3: Produção de Ferro (1935/1939)

\begin{tabular}{ccc}
\hline Anos & Produção (toneladas) & Índice $(1935=100)$ \\
\hline 1935 & 14.588 & 100 \\
\hline 1936 & 17.850 & 122 \\
\hline 1937 & 18.534 & 127 \\
\hline 1938 & 19.034 & 130 \\
\hline 1939 & 19.486 & 133 \\
\hline
\end{tabular}

Fonte: (PALMIER, 1940, p. 178).

Tabela 4: Produção de Aço (1935/1939)

\begin{tabular}{ccc}
\hline Anos & Produção (tonelada) & Índice $(1935=100)$ \\
\hline 1935 & 17.709 & 100 \\
\hline 1936 & 20.485 & 116 \\
\hline 1937 & 20.758 & 117 \\
\hline 1938 & 22.425 & 125 \\
\hline 1939 & 21.923 & 124 \\
\hline
\end{tabular}

Fonte: (PALMIER, 1940, p. 178).

\section{A instalação da Companhia Nacional de Cimento Portland em São Gonçalo}

No país, até a segunda década do século XX, existia apenas uma indústria de produção de cimento, localizada em Perus, São Paulo. A intenção de construção de uma fabrica de cimento na região fluminense, segundo Victor Prochnik, já existia desde meados da década de 1920 (PROCHNIK, 1985, p. 428), estimulada pelo aumento do consumo aparente do produto em função da modernização da então capital federal e também de cidades como São Paulo (Tabela 5). 


\begin{tabular}{lc}
\hline Ano & $\begin{array}{c}\text { Consumo } \\
\text { aparente }\end{array}$ \\
\hline 1919 & 198,4 \\
\hline 1920 & 173,0 \\
\hline 1921 & 156,9 \\
\hline 1922 & 319,6 \\
\hline 1923 & 223,4 \\
\hline 1924 & 317,2 \\
\hline 1925 & 336,5 \\
\hline
\end{tabular}

Fonte: Serviço de Estatística do Sindicato Nacional da Indústria do Cimento. Apud: VILLELA e SUZIGAN, 1973, p. 437.

Uma das principais dificuldades para a instalação de uma indústria de cimento no Brasil era referente, sem dúvida, à disponibilidade da matéria prima calcária. Em 1928, a empresa Cement Lone Star, de capital norte-americano, anunciou a descoberta de uma importante reserva de calcário na Fazenda São José, em Itaboraí, município vizinho à cidade de São Gonçalo. Após a descoberta, em 1931, teria início a construção de uma fábrica de grande porte em Guaxindiba, região limítrofe entre os dois municípios, mas que pertencia à São Gonçalo.

27 As negociações para a aquisição da propriedade em São José, entre os empresários americanos e os donos da fazenda, tiveram o seu início ainda em 1930, logo após a descoberta das reservas de calcário. Segundo reportagem do jornal Diário de Notícias,

"em julho de 1930 os senhores Ernesto Coube, Carlos Euler e sobrinhos, como proprietários da fazenda São José, município de Itaborahy, foram procurados por uns americanos, que pretendiam explorar a alludida fazenda. Dahi resultou entrarem os mesmos em negociações para o estudo e explorações da mesma, onde estão localizadas as jazidas de calcáreos. Após dois mezes, accordaram os fazendeiros em cederem a propriedade, pelo prazo de seis mezes, por opção, entrando os americanos com 20 contos de réis, para garantia das sondagens preliminares, e, no caso de verificar-se a existência de calcareo, estes ficaria, com a fazenda de São José, pelo preço de cem mil dólares. Constatada, emfim, a existência daquelle minério, calculou-se a zona em que o mesmo se encontra em 11 milhões de metros cúbicos. Foi então celebrada a compra da situação, pelo preço acima entabolado".

Através do decreto $\mathrm{n}^{\circ}$ 2.622, de 24 de julho de 1931, a empresa Lone Star recebeu importantes concessões do poder público municipal e estadual para que desse início à 
construção de uma fábrica de cimento no local, a Companhia Nacional de Cimento Portland - CNCP. Pelo decreto, foi concedido: 1) isenção para todos os impostos estaduais e municipais durante 10 anos, contados do início do funcionamento da fábrica; 2) direito de desapropriação de terrenos e benfeitorias necessárias à instalação da fábrica (linha férrea, canal no rio Guaxindiba e porto); 3) cessão de terrenos públicos, mediante arrendamento ou compra e venda a prazo, pelo preço de avaliação oficial; entre outros benefícios.

A ata da primeira Assembleia de Acionistas da CNCP, realizada no dia 28 de julho de $1931 \mathrm{e}$ divulgada em Diário Oficial, destacava os principais objetivos da empresa norteamericana na construção da fábrica em Guaxindiba, em particular os métodos considerados mais eficientes e econômicos para a utilização do calcário da bacia de São José, levando em consideração à proximidade com a cidade do Rio de Janeiro, principal centro consumidor:

“(...) 1ํㅡ, extrair o calcário da Fazenda São José; 2º transportá-lo para a Fazenda Guaxindiba por intermédio de uma estrada de ferro industrial construída especialmente para esse fim; $3^{\circ}$, construir uma fábrica na Fazenda Guaxindiba, com todos os requisitos essenciais ao preparo definitivo do cimento Portland; $4^{\circ}$, distribuir o cimento para os diversos mercados do Estado do Rio por intermédio da Leopoldina Railway; $5^{\circ}$, construir um canal de cerca de $1 \frac{1 / 2}{2}$ a 2 quilômetros de comprimento ligando a fábrica ao Rio Guaxindiba; $6^{\circ}$, transportar o cimento destinado ao Distrito Federal a granel através do canal e o Rio Guaxindiba atravessando a Baía de Guanabara até a seção apropriada do novo Porto do Rio de Janeiro".

Para viabilizar o funcionamento da extração do calcário da bacia de São José, a CNCP construiu uma linha férrea própria para o transporte da matéria prima, de Itaboraí até a fábrica. Além da ferrovia construída pela própria $\mathrm{CNCP}$, estava previsto no projeto também a utilização da ferrovia Leopoldina Railway (SILVA, CRUZ e CUNHA, 2016).

Devido a fatores de ordem geográfica e econômica, a fábrica não seria implantada no mesmo local da extração do calcário (Itaboraí), mas sim na cidade de São Gonçalo. 0 bairro de Guaxindiba foi escolhido pelos empresários norte-americanos, devido a sua localização estratégica, pois, para o transporte do produto até o novo porto do Rio de Janeiro, era necessária apenas a construção de um canal que ligaria a fábrica ao rio Guaxindiba. 0 rio desembocava na Baía de Guanabara, e dali, o cimento seria levado até o porto do Rio de Janeiro e de lá distribuído para outras regiões.

Com relação ao maquinário da $\mathrm{CNCP}$, a imprensa da época destacava a complexidade do espaço fabril, que contava com mais de 80 operações distintas. As máquinas utilizadas provenientes dos EUA - eram todas movidas por eletricidade. Segundo o Diário de Notícias, “(...) a energia electrica necessária ao funcionamento da fábrica seria bastante para fornecer a eletricidade sufficiente às necessidades domesticas e caseiras diárias de uma cidade como Bello Horizonte".

Para a construção do canal do rio Guaxindiba, a CNCP contratou os serviços da Companhia Nacional de Construções Civis e Hidráulicas. O relatório anual de 1931 da empresa mencionava ao contrato assinado para a realização das obras de dragagem do canal de Guaxindiba e informava que as obras tiveram início em setembro daquele ano, simultaneamente à construção da própria fábrica. No mesmo documento, apresentado aos acionistas em março de 1932, era dado destaque, além das obras de construção da empresa, à depressão econômica internacional e à queda no consumo de cimento no Distrito Federal (Tabela 6). Contudo, o parecer da diretoria da CNCP se posicionava 
favoravelmente à continuidade das obras da fábrica, entendendo que a crise e a consequente queda no consumo de cimento eram momentâneas.

Tabela 6: Consumo aparente de cimento (1926-1932)

\begin{tabular}{cc}
\hline Ano & $\begin{array}{c}\text { Consumo } \\
\text { aparente }\end{array}$ \\
\hline 1926 & 409,7 \\
\hline 1927 & 496,6 \\
\hline 1928 & 544,2 \\
\hline 1929 & 631,5 \\
\hline 1930 & 471,7 \\
\hline 1931 & 281,4 \\
\hline 1932 & 310,0 \\
\hline
\end{tabular}

Fonte: Serviço de Estatística do Sindicato Nacional da Indústria do Cimento. Apud: VILLELA e SUZIGAN, 1973, p. 437.

Em março de 1932, com a construção da linha férrea ainda em andamento, o jornal Diário de Notícias noticiou a demissão de 400 operários da CNCP que trabalhavam na construção da estrada de ferro que ligava a fábrica à bacia calcária de São José. As demissões foram justificadas pela paralisação das obras devido à dificuldade na aquisição de terras da fazenda Itahytindiba, prevista para passar a linha férrea. Após julgar o caso, o governo estadual determinou a desapropriação das terras da fazenda em favor da CNCP, declarando ser a construção da estrada de ferro industrial de "utilidade pública". A faixa de terra desapropriada tinha as dimensões de 30 metros de largura e 1.000 metros de comprimento. Segundo o jornal,

“da faixa desapropriada não se poderá utilizar a concessionária senão para a construcções e installações necessarias à passagem da estrada de ferro industrial, à sua conservação, segurança de tráfego, e bem assim, para passagem aerea ou subterrânea de fios e cabos de transmissão de luz, força e telephones e outros conductores, inclusive os de água; ficando-lhe expressamente prohibida, para qualquer outro fim, a exploração do solo e sub-solo, a que a referida faixa correspondia, e, assim, não podendo a mesma aproveitar-se para sua indústria de fabricação de cimento, de qualquer mineração ou calcareo ali existentes, salvo se os adquirir pelos meios de direito".

Em 1933, o relatório apresentado aos acionistas destacava a utilização do canal do rio Guaxindiba e do cais, bem como a exploração dos depósitos de calcário, que se encontrava bastante avançada. Além disso, informava sobre o desenvolvimento comercial da região no entorno da fábrica. Segundo o documento,

“(...) a construção da fábrica desenvolveu considerável atividade comercial nas vizinhanças do local em que se acha instalada, e todos os objetos, com exceção da maquinaria apropriada para o fabrico do cimento, tem sido adquiridos no próprio 
local, em Niterói e na Capital Federal. Foi empregada, durante o ano, uma média de mil duzentos e setenta e nove homens". causado pelo quebra da Bolsa de Nova York em 1929, a CNCP seria inaugurada em maio de 1933, sendo noticiada nos principais jornais fluminenses, a fabricação do cimento da CNCP - Mauá. O nome do cimento era uma homenagem a Irineu Evangelista de Souza, barão de Mauá. Segundo o relatório anual de 1933,

“o primeiro cimento foi fabricado no dia 15 de abril. 0 nome Mauá foi adotado para o produto, e o cimento foi entregue aos freguezes pela primeira vez em 15 de maio. É com satisfação que se pode informar sôbre a rápida aceitação do cimento Mauá por engenheiros, arquitetos e firmas empreiteiras, e que os resultados das várias análises efetuadas, tanto nos laboratórios oficiais como não oficiais, demonstraram que este cimento supera os requisitos das especificações "standard" neste e em outros países. Pelas contas apresentadas, e após exame, aprovadas pelo conselho fiscal, poderão verificar VV. SS. Os resultados das operações relativos ao ano próximo passado, e notarão a posição financeira da companhia, e as grandes somas que foram investidas na construção da instalação. Em vista do período inicia operações, e as despesas que tiveram que ser feitas, os lucros não são ainda suficientes para garantir a distribuição de dividendos. $\mathrm{Na}$ assembleias extraordinária dos acionistas, realizada em 23 de dezembro, ficou deliberado de se aumentar o capital da companhia de 10.000 para 40.000 contos".

A CNCP, em seu primeiro ano de funcionamento (1933), produziu 61.000 toneladas de cimento, um número relativamente pequeno se comparado ao fabricado naquele ano em Perus. Entretanto, se observarmos a quantidade produzida no primeiro da fábrica paulista, veremos que, a produção da CNCP foi superior. A revista $O$ Observador Econômico $e$ Financeiro fez um levantamento da produção da CNCP - Mauá nos seus primeiros três anos de funcionamento:

Tabela 7: Produção e utilização do cimento CNCP- Mauá (1933 - 1935)

\begin{tabular}{cccc}
\hline Ano & Produção & $\begin{array}{c}\text { Cimento utilizado } \\
\text { Cimento no Rio de } \\
\text { Janeiro }\end{array}$ & $\begin{array}{c}\text { Cimento utilizado } \\
\text { em outros estados }\end{array}$ \\
\hline 1933 & 61.000 tons & 7.000 tons & 59.000 tons \\
\hline 1934 & 139.000 tons & 18.000 tons & 121.000 tons \\
\hline 1935 & 164.000 tons & 23.000 tons & 141.000 tons \\
\hline
\end{tabular}

Fonte: O Observador Econômico e Financeiro, maio - n 16, p. 46, 1937.

No segundo ano de funcionamento, a produção da CNCP mais do que duplicou em relação ao primeiro ano, e sua contribuição para a produção de cimento nacional foi de $43 \%$. No terceiro ano no terceiro ano, a produção aumentou apenas $18 \%$, mas sua contribuição para a produção nacional se manteve estável em relação ao ano anterior (45\%). 
Tabela 8: Produção de cimento no Brasil na década de 1930

\begin{tabular}{ll}
\hline Ano & $\begin{array}{l}\text { Produção } \\
\text { Nacional }\end{array}$ \\
\hline 1926 & $13.382,00$ \\
\hline 1927 & $54.623,00$ \\
\hline 1928 & $87.964,00$ \\
\hline 1929 & $96.208,00$ \\
\hline 1930 & $87.160,00$ \\
\hline 1931 & $167.115,00$ \\
\hline 1932 & $149.453,00$ \\
\hline 1933 & $225.680,00$ \\
\hline 1934 & $323.909,00$ \\
\hline 1935 & $366.261,00$ \\
\hline 1936 & $485.064,00$ \\
\hline 1937 & $571.452,00$ \\
\hline 1938 & $617.896,00$ \\
\hline 1939 & $697.793,00$ \\
\hline 1940 & $744.673,00$ \\
\hline 1942 & $767.506,00$ \\
\hline 1943 & $752.833,00$ \\
\hline
\end{tabular}

Fonte: O Observador Econômico e Financeiro, maio - n 16, p. 46, 1937 e Sindicato Nacional da Indústria de Cimento (SNIC- 1983)

Com base na tabela 8, podemos perceber que, em 1926, a indústria de cimento brasileira, representada por apenas uma empresa (CBCP - Perus), produzia apenas 13.000 toneladas de cimento. Em 1930, mesmo ainda com uma única companhia, a produção cresceu cerca de 670\%, chegando à quantia de 87.000 toneladas anual. Após a implantação da CNCP, a produção aumentou significativamente, chegando em 1935 a uma produção de cerca de 366.000 toneladas, o que representava um crescimento de mais de $100 \%$ em relação ao ano de 1930.

Com o aumento do consumo de cimento, em 1934, foi planejada a primeira obra de ampliação das instalações da companhia, com a instalação de um segundo forno. Após as obras de ampliação da CNCP, o jornal Diário de Notícias, no dia 06 de dezembro de 1935, noticiava o funcionamento do segundo calcinador, possibilitado o aumento da produção de cimento:

"Novo e vigoroso impulso foi dado ao desenvolvimento do nosso progresso industrial, no dia 19 de novembro passado, quando começou a funccionar o segundo calcinador da Companhia Nacional de Cimento Portland, à qual assim augmenta consideravelmente a capacidade pructiva de sua fábrica installada em Guaxindiba, no Estado do Rio (...). A fabrica, com esse augmento, te agora a capacidade para produzir annualmente sete milhões de saccos, ou seja... 300.000 toneladas de cimento "Mauá".

41 Concomitante à instalação dos calcinadores na fábrica, que aumentaria a produção de cimento, a jazida de calcário, na fazenda São José, recebeu novos maquinários, que também possibilitariam o prosseguimento na extração da matéria prima, uma vez que o terreno desnivelado não possibilitava a extração do calcário com os métodos utilizados na 
época. Além disso, o novo maquinário contribuiria para uma mais rápida extração do calcário Segundo o Diário de Notícias,

"ao mesmo tempo a Companhia Nacional está installando na sua pedreira, situada em São José, no município de Itaborahy, a maior escavadeira ate hoje fabricada no mundo. Essa escavadeira pesa 1.500 toneladas e é conhecida como sendo "a maior coisa no mundo que anda sobre dois pés", por ser movida de um logar para o outro por meio de duas enormes sapatas mecânicas, installadas de cada lado. Uma caçamba com capacidade para 10 metros cúbicos suspensa na ponta de uma haste de 75 metros de comprimento permitte attingir uma área de 150 metros de diâmetro e empilhar material escavado a uma grande altura.Essa gigantesca peça mecânica, especialmente desenhada e fabricada para a Companhia Nacional, torna possível no Brasil a producção de cimento em larga escala (...) os depósitos calcareos, estão localizados em região onde as desigualdade topographicas são bem accentuadas e o calcareo esta encoberto por collinas de terra, verdadeiro outeiros, que em alg.uns casos attingem 50 metros de altura. Realmente, tornou-se necessário resolver um verdadeiro problema, o de mover montanhas, para poder attingir os depósitos subterrâneos de pedra calcarea".

O jornal destacava, ainda, a dificuldade na escavação da bacia calcária de São José. A solução para o problema da extração do calcário foi resolvida com a utilização de uma cavadeira, especialmente projetada para a CNCP - Mauá, permitindo a ampliação da capacidade de produção.

Tabela 9: Produção de cimento (CNCP - Mauá)

\begin{tabular}{cc}
\hline Ano & $\begin{array}{c}\text { Produção de cimento } \\
\text { (CNCP - Mauá) }\end{array}$ \\
\hline 1933 & 61.115 tons. \\
\hline 1934 & 139.672 tons. \\
\hline 1935 & 164.071 tons. \\
\hline 1936 & 223.644 tons. \\
1937 & 239.785 tons. \\
\hline 1938 & 250.937 tons. \\
\hline 1939 & 269.817 tons. \\
\hline 1940 & 279.010 tons. \\
\hline 1941 & 278.936 tons. \\
\hline 1942 & 278.152 tons. \\
\hline
\end{tabular}

Fonte: O Observador Econômico e Financeiro, abril - nº 95, p. 49, 1943.

As obras de ampliação da CNCP possibilitaram um aumento considerável na produção anual de cimento da empresa. Conforme podemos perceber a partir da análise da tabela 9 , entre 1935 (ano que a fábrica estava em fase de ampliação) e 1936, ocorreu um aumento 
de mais de $70 \%$ na sua produção, tendo uma participação de $46 \%$ na produção nacional foi de $46 \%$.

Em junho de 1936, a CNCP lançou um novo tipo de cimento no mercado, tendo o tempo reduzido para a secagem do produto o seu diferencial. 0 novo cimento tinha o nome "Incor". Enquanto o cimento da marca "Mauá" demorava de cinco a sete dias para ter o processo de secagem concluído, o "Incor" necessitava de apenas um a dois dias para ficar totalmente seco. Tal característica era muito importante para a duração final da obra, pois o tempo de secagem, muitas das vezes impossibilitava o seu prosseguimento, tendo que esperar o processo de secagem do cimento ser concluído para continuar o serviço. Segundo o jornal $O$ Radical,

"ao lançar no mercado o cimento "INCOR" que é um cimento Portland aperfeiçoado e garantido satisfazer as especificações para cimentos portland de endurecimento rápido, pomos ao alcance da industria de construcções um cimento que produz um concreto prompto para uso em 24 horas depois de collocado e ao mesmo tempo assegura resistência e durabilidade. Este cimento é submettido a processos de fabricação que augmentam a sua efficiencia, não contendo misturas addiccionaes de qualquer espécie".

Na década de 1930, conforme apresentado na tabela 10, o consumo aparente do cimento no Brasil, considerando a participação da CNCP, apresentaria um crescimento bastante elevado.

Tabela 10: Consumo aparente de cimento com o funcionamento da CNCP - Mauá (1933- 1942)

\begin{tabular}{cc}
\hline Ano & $\begin{array}{c}\text { Consumo } \\
\text { Aparente }\end{array}$ \\
\hline 1933 & 339,4 \\
\hline 1934 & 449,6 \\
\hline 1935 & 480,4 \\
\hline 1936 & 563,3 \\
\hline 1937 & 646,3 \\
\hline 1938 & 667,5 \\
\hline 1939 & 732,6 \\
\hline 1940 & 759,2 \\
\hline 1941 & 776,8 \\
\hline 1942 & 818,8 \\
\hline
\end{tabular}

Fonte: O Observador Econômico e Financeiro, abril - nº 95, p. 49, 1943 e Sindicato Nacional da Indústria de Cimento (SNIC- 1983).

O relatório anual de 1938, apresentado na assembleia de acionistas em março de 1939, destacava os melhoramentos realizados tanto na fábrica quanto na pedreira. Dentre as melhorias era dado destaque a instalação de uma "excavadeira com tração de lagarta, 
movida à eletricidade (...) afim de mais eficientemente atender às necessidades da produção da pedra calcarea".

Devido às obras e os novos maquinários instalados, a fábrica e a pedreira passaram ter um grande consumo de energia elétrica, o que impossibilitou a prestação do serviço da então empresa fornecedora. A parir de dezembro de 1938, a empresa de eletricidade seria incapaz de suprir a energia necessária para o funcionamento da fábrica e da pedreira, pois todas as máquinas eram acionadas exclusivamente com eletricidade. Segundo publicação no Diário Oficial

“(...) sendo impraticável obter energia elétrica de outras empresas, a Companhia foi obrigada a inverter avultada quantia na aquisição e instalaçã de uma uzina termoelétrica, de capacidade suficientemente elevada para garantir a produção de toda a energia necessária à fabricação do seu produto. A uzina elétrica assumiu o fornecimento da carga total da Fábrica em 26 de dezembro de 1938, dia em que foi desligada a força da empresa fornecedora.

Afim de garantir o funcionamento da referida usina, foi necessário perfurar um poço para suprir água em suficiência para as caldeiras, bem assim como construir um tanque para armazenamento de mil e quinhetas toneladas de óleo combustível. Para o encarregado da uzina, foi construída uma residência nos terrenos da Companhia, em Guaxindiba".

Para a instalação da termelétrica, a CNCP - Mauá conseguiu do governo federal isenção de taxas aduaneiras, por um período de dez anos, para todo material importado e empregado na instalação e funcionamento tanto da fábrica quanto da pedreira.

No final do ano de 1941, foi terminada a terceira obra de ampliação do parque industrial da fábrica, que contava com a instalação de um terceiro calcinador. O objetivo era aumentar em cerca de $20 \%$ a capacidade da fábrica, com a produção superior a 400.000 toneladas de cimento por ano. Porém, no relatório anual de 1942, era apresentado o problema que impossibilitou a produção na quantidade planejada:

“o fator principal que contribuiu para este resultado foi a falta de óleo combustível para o calcinação das matérias primas e para as caldeiras da usina termo-elétrica. Esta falta tornou-se aguda no princípio de maio, e durante os quatro meses subseqüentes foi tão critica, que a produção de cimento teve que ser drasticamente reduzida, tendo em duas ocasiões cessado inteiramente por um período total de treze dias".

Para reverter a situação, a CNCP - Mauá reduziu o consumo de óleo combustível e pleiteou junto ao Conselho de Águas e Energia Elétrica, o fornecimento de energia hidroelétrica pela Companhia Brasileira de Energia Elétrica. Com o fornecimento de energia pela empresa, foi eliminado o consumo de óleo combustível na produção de energia pela usina da fábrica, possibilitando a utilização do óleo disponível exclusivamente para a calcinação da matéria prima. 
Tabela 11: Produção de cimento pela CNCP- Mauá, produção nacional, importação e o consumo aparente. (1933-1942)

\begin{tabular}{ccccc}
\hline Ano & $\begin{array}{c}\text { Produção } \\
\text { CNCP- Mauá }\end{array}$ & Produção nacional & Importação & $\begin{array}{c}\text { Consumo } \\
\text { Aparente }\end{array}$ \\
\hline 1933 & 61.115 & $225.680,00$ & $113.870,00$ & 339,4 \\
\hline 1934 & 139.672 & $323.909,00$ & $125.702,00$ & 449,6 \\
\hline 1935 & 164.071 & $366.261,00$ & $115.389,42$ & 480,4 \\
\hline 1936 & 223.644 & $485.064,00$ & $83.013,11$ & 563,3 \\
\hline 1937 & 239.785 & $571.452,00$ & $79.280,45$ & 646,3 \\
\hline 1938 & 250.937 & $617.896,00$ & $54.091,95$ & 667,5 \\
\hline 1939 & 269.817 & $697.793,00$ & $41.098,33$ & 732,6 \\
\hline 1940 & 279.010 & $744.673,00$ & $22.786,15$ & 776,8 \\
\hline 1941 & 278.936 & $767.506,00$ & $18.307,66$ & 818,8 \\
\hline 1942 & 278.152 & $752.833,00$ & $74.813,62$ & .2 \\
\hline
\end{tabular}

Fonte: Serviço de Estatística do Sindicato Nacional da Indústria do Cimento. Apud: VILLELA e SUZIGAN, 1973, p. 437; SINDICATO NACIONAL DA INDÚSTRIA DE CIMENTO.

\section{Conclusão}

51 Ao longo deste artigo, procuramos destacar a instalação da Companhia Nacional de Cimento Portland (CNCP), no bairro de Guaxindiba, no contexto do processo de industrialização de São Gonçalo, entre as décadas de 1930 e 1940. Nesse período, o município fluminense passou por um intenso processo de urbanização, levando à instalação de diversas fábricas na região, responsáveis por uma produção bastante diversificada, levando - com certo ufanismo e exagero - a dar ao município a alcunha de "Manchester Fluminense". Em nossa hipótese, razões de ordem geográfica - a sua localização próxima à Baia de Guanabara - e econômica - a concessão de diversos incentivos fiscais - levaram a sua instalação em São Gonçalo e não em Itaboraí, região na qual estavam localizadas as reservas de calcário exploradas pela empresa na produção de cimento.

\section{BIBLIOGRAFIA}

ARAÚJO, Victor e MELO, Hildete. O processo de esvaziamento industrial em São Gonçalo no século XX: auge e declínio da "Manchester Fluminense". Cadernos do desenvolvimento Fluminense, $\mathrm{n}^{\circ}$ 4, pp. 65-87, 2014. 
CAMPOS, Pedro Henrique Pedreira. Estranhas Catedrais: as empreiteiras brasileiras e a ditadura civil-militar, 1964-1988. Niterói: Ed. UFF, 444 p., 2014.

CHAVES, Marcelo. Da periferia ao centro da (o) capital: perfil dos trabalhadores do primeiro complexo cimenteiro do Brasil. São Paulo, Dissertação de Mestrado em História. Programa de Pós-Graduação em História, Universidade Estadual de Campinas, 285 p., 2005.

FEITOSA, Paulo César Machado. A indústria do cimento no Brasil: um estudo de casos em concentração industrial. São Paulo, Dissertação de Mestrado em Administração. Programa de Pós-Graduação em Economia Aplicada, Fundação Getúlio Vargas, 238 p., 1982.

LESSA, José Luís Honorato. A paisagem revelada: natureza da concentração industrial em São Gonçalo (RJ) - crise ou reestruturação da indústria local? São Gonçalo, Dissertação de Mestrado em História, Programa de Pós-Graduação em História Social do Território, Universidade do Estado do Rio de Janeiro, 2010.

PALMIER, Luiz. São Gonçalo Cinquentenário. Rio de Janeiro: IBGE, 237 p., 1940.

PROCHNIK, Victor. As possibilidades das empresas nacionais: o caso da indústria do cimento. Pesquisa e Planejamento Econômico, vol., 15, nº 2, pp. 419-446, 1985.

; PEREZ, Adriana; SILVA, Carla Maria de Souza. A Globalização na Indústria de Cimento, 1998. <http://www.ie.ufrj.br/images/cadeias_produtivas/a_ globalizacao_na_industria_do_cimento.pdf $>$. Acessado em 16 de janeiro de 2018.

SANTOS, Leandro. A indústria de cimento no Brasil: origens, consolidação e internacionalização. Revista Sociedade \& Natureza, vol. 23, nº 1, pp. 77-94, 2011.

SILVA, Marcelo Werner; CRUZ, Ana Carolina Soares; CUNHA, Marianna Rocha Antunes. A implantação ferroviária no Estado do Rio de Janeiro: 1854-1900. < http://www.uff.br/ivspesr/ images/Artigos/ST04/ST04.2_Marcelo_Werner_da_Silva.pdf>. Acessado em 13 de julho de 2016.

SINDICATO NACIONAL DA INDÚSTRIA DO CIMENTO. A História do cimento no Brasil. < www.snic.org.br/pdf/Historia_do_Cimento_no_Brasil.pdf $>$ Acessado em 23 de dezembro de 2017.

SUZIGAN, Wilson. Indústria brasileira: origem e desenvolvimento. São Paulo: Hucitec/Unicamp, 424 p., 2000.

e VILLELA, Annibal Villanova. Política do Governo e Crescimento da Economia Brasileira (1889-1945). Rio de Janeiro: IPEA/INPES, 468 p., 1973.

\section{RESUMOS}

$\mathrm{O}$ artigo tem como objetivo analisar a instalação da Companhia Nacional de Cimento Portland (CNCP), em São Gonçalo, entre os anos de 1931 e 1942. A empresa, subsidiária da Lone Star, de capital norte-americano, decidiu pela construção de uma fábrica de cimento, em Guaxindiba, região limítrofe entre São Gonçalo e Itaboraí, após a descoberta de jazidas de calcário na bacia de São José, localizada em Itaboraí. Defendemos a hipótese de que motivos de ordem geográfica e econômica levaram a CNCP a se instalar em São Gonçalo e não na região onde se encontrava a matéria prima para a produção de cimento. Entre as fontes trabalhadas, estão os relatórios anuais de acionistas da empresa e periódicos da época.

This article intends to analyze the installation of the National Portland Cement Company (CNCP), in São Gonçalo, between 1931 and 1942. The company, a subsidiary of Lone Star, of north american capital, decided to build a factory of cement, in Guaxindiba, a border region between 
São Gonçalo and Itaboraí, after the discovery of limestone deposits in the São José basin, located in Itaboraí. We defend the hypothesis that geographic and economic reasons led CNCP to settle in São Gonçalo and not in the region where the raw material for cement production was located. Among the sources worked are the annual reports of company shareholders and periodicals of the time.

El artículo tiene como objetivo analizar la instalación de la Compañía Nacional de Cemento Portland (CNCP), en São Gonçalo, entre los años 1931 y 1942. La empresa, subsidiaria de Lone Star, de capital estadounidense, decidió por la construcción de una fábrica de cemento, en Guaxindiba, región limítrofe entre São Gonçalo e Itaboraí, tras el descubrimiento de yacimientos de calcáreo en la cuenca de San José, ubicada en Itaboraí. Defendemos la hipótesis de que motivos de orden geográfico y económico llevaron a la CNCP a instalarse en São Gonçalo y no en la región donde se encontraba la materia prima para la producción de cemento. Entre las fuentes trabajadas, están los informes anuales de accionistas de la empresa y periódicos de la época.

L'objectif de cet article est d'analyser l'installation de la Compagnie Nationale de Ciment Portland (CNCP), à São Gonçalo, entre 1931 et 1942. L'entreprise, filiale de Lone Star, de capital nord-américain, a décidé de construire une usine de ciment à Guaxindiba, une région frontalière entre São Gonçalo et Itaboraí, après la découverte de gisements de calcaire dans le bassin de São José, situé à Itaboraí. Nous soutenons l'hypothèse selon laquelle des raisons géographiques et économiques ont conduit la $\mathrm{CNCP}$ à s'installer à São Gonçalo et non dans la région où se trouvait la matière première pour la production de ciment. Parmi les sources travaillées, il y a des rapports annuels des actionnaires de la société et des périodiques de l'époque.

\section{ÍNDICE}

Mots-clés: Industrialisation - São Gonçalo - Compagnie Nationale de Ciment Portland.

Keywords: Industrialization - São Gonçalo - National Portland Cement Company.

Palabras claves: Palabras clave: Industrialización - São Gonçalo - Compañía Nacional de Cemento Portland.

Palavras-chave: Industrialização - São Gonçalo - Companhia Nacional de Cimento Portland.

\section{AUTOR}

\section{RAFAEL VAZ DA MOTTA BRANDÃO}

Doutor em História Social (UFF). Universidade do Estado do Rio de Janeiro. Faculdade de Formação de Professores. Departamento de Ciências Humanas. Professor visitante PNPD/CAPES. E-mail: rafabrandao@uol.com.br 